\title{
Synthesis and Properties of a Novel Brush-type Copolymers Bearing Thiophene Backbone and 3-( $N$-carbazolyl)propyl Acrylate Side Chains for Light-emitting Applications
}

\author{
By Jie Shen, Hayakazu MASAOKA, Kousuke TSUCHIYA, and Kenji OGINO*
}

\begin{abstract}
A new light-emitting and hole transporting copolymer 2,5-Poly(3-[1-ethyl-2-(2-[poly(3-(N-carbazolyl)propyl acrylate)]propionate)] thiophene) (PT- $g$-PCPA) was prepared via atom transfer radical polymerization (ATRP) of a 3-(N-carbazolyl)propyl acrylate (CPA) monomer, initiated by a macroinitiator with ATRP initiating sites distributed along polythiophene (PT) backbone. The resulting polymers were characterized by gel permeation chromatography (GPC), nuclear magnetic resonance $\left({ }^{1} \mathrm{H}\right.$ and ${ }^{13} \mathrm{C}$ NMR) spectroscopy and differential scanning calorimetry (DSC). The optical properties of polymers were investigated by UV-vis and fluorescence analyses. The electrochemical properties of polymers were investigated by cyclic voltammetric (CV) measurements. The results confirmed that the introduction of the PCPA side chains trapped the polythiophene backbone in a "solution-like" conformation, which inhibited the aggregation of polythiophene backbone effectively. Additionally, the energy transfer process from PCPA side chains to the PT backbone in both solution and film states were also evidenced. Electroluminescence devices fabricated from the copolymer demonstrated that copolymer could act as both light emissive and hole-transporting materials.

KEY WORDS: Polythiophene / 3-(N-Carbazolyl)propyl Acrylate / Graft Copolymer / Light-emitting Material / Atom Transfer Radical

Polymerization /
\end{abstract}

The need for large area displays and patterned light sources has prompted the development of polymeric light-emitting diodes (PLEDs) that typically consist of conjugated polymers. Ever since the first report about PLEDs in $1990,{ }^{1}$ significant efforts have been devoted to developing new PLED materials with better properties, such as brightness, quantum efficiency, and optical and electron stabilities. ${ }^{2-4}$

Polythiophenes (PTs) are one of the most studied and important classes of $\pi$-conjugated polymeric materials because of their excellent environmental stability, thermal stability, processability, and mechanical strength, as well as ease of fabrication. ${ }^{5-9}$ However, even though they can easily produce a red color that is difficult to achieve with other conjugated polymers, their application as emissive materials in PLEDs has been limited due to the low photoluminescent (PL) quantum efficiency in the solid state and poor electroluminescent (EL) efficiency. ${ }^{10-13}$

The low performance of PTs was thought to be caused primary by the severe stacking of polythiophene chains in the solid state and it has been demonstrated that the efficiency could be significantly increased by introducing side chains such as alkyl substituents, alkoxy substituents, alkoxycarbonyl substituents, dentric moiety, as well as polymers onto PT to separate the PT backbone. Previously, we also successfully prepared a highly fluorescent polythiophene graft copolymer containing a PT backbone and polystyrene sidearms having desired grafting density and sidearm length. ${ }^{14}$ However, in most of these works, the side chains are inert segments, lacking of optical or electrical activities, and are used only to provide steric hindrance between two adjacent PTs, which limits the further improvement of the performance of PT based LEDs.

Arylamine derivatives such as carbazole are well known as good hole transporting materials, because of the electrondonating nature related to the nitrogen in carbazole ${ }^{15-17}$ and stabilizing capability for radical cations. The polymers with carbazole moieties in the main chain or as side pendant group had been reported recently. ${ }^{18-22}$ In this study, a new graft copolymer 2,5-Poly(3-[1-ethyl-2-(2-[poly(3-( $N$-carbazolyl)propyl acrylate)]propionate)]thiophene) (PT-g-PCPA) was designed and synthesized by typical ATRP conditions. Because of carbazole-containing molecular structure, the PCPA was thought to be excellent in hole transporting properties. ${ }^{23}$ The PCPA side chain and the PT backbone are expected to retain their respective hole-transporting and emitting properties simultaneously. In addition, the PCPA side chains are also expected to perform the functions of solubilization, aggregation suppression, and energy transfer. Here, the synthesis, optical and EL properties of obtained copolymer were investigated.

\section{EXPERIMENTAL}

\section{Materials}

The starting materials 3-thiopheneethanol (98\%) and 2bromopropionyl bromide (98\%) were commercially obtained from Tokyo Kasei. Iron(III) chloride $\left(\mathrm{FeCl}_{3}\right)$, carbazole, 1,3dibromopropane, benzyltriethylammonium chloride (BTEAC), benzene, sodium hydroxide, acrylic acid, sodium hydrogen carbonate, $N, N, N^{\prime}, N^{\prime \prime}, N^{\prime \prime}$-pentamethyldiethyltriamine 
(PMDETA, 98\%), and copper (I) bromide ( $\mathrm{CuBr}, 95 \%)$ were purchased from Wako. All these reagents and solvents were used without further purification unless stated otherwise. $\mathrm{N}, \mathrm{N}$ Dimethylformamide (DMF) (Wako, 98\%) and styrene (Wako, 99\%) were dried over $\mathrm{CaH}_{2}$ and distilled at reduced pressure before use.

\section{3-[1-Ethyl-2-(2-bromopropionate)]thiophene (TBr) (2)}

In a flask placed in an ice bath, 3-thiopheneethanol (10.0 g, $78 \mathrm{mmol})$ was dissolved in $\mathrm{CH}_{2} \mathrm{Cl}_{2}(100 \mathrm{~mL})$. 2-Bromopropionyl bromide $(21.4 \mathrm{~g}, 100 \mathrm{mmol})$ and triethylamine $(14 \mathrm{~mL}$, $100 \mathrm{mmol}$ ) were added dropwise to the flask. After stirred for $30 \mathrm{~min}$, the cooling bath was removed. The solution was stirred for $12 \mathrm{~h}$ at room temperature, and then washed with water $(200 \mathrm{~mL})$. The organic layer was dried over anhydrous $\mathrm{MgSO}_{4}$ (Wako), filtered and then the solvent was removed. The residual product was purified by column chromatography (silica gel, $\left.\mathrm{CH}_{2} \mathrm{Cl}_{2}\right)$. $\mathrm{TBr}(18.4 \mathrm{~g}$, yield $90 \%$ ) was isolated as colorless oil.

${ }^{1} \mathrm{H}$ NMR $\left(\mathrm{CDCl}_{3}, \delta, \mathrm{ppm}\right): 1.82\left(\mathrm{~d}, 3 \mathrm{H}, \mathrm{CHBrCH}_{3}\right), 2.83(\mathrm{t}$, $\left.2 \mathrm{H}, \mathrm{CH}_{2} \mathrm{CH}_{2} \mathrm{OCO}\right), 4.31-4.45\left(\mathrm{~m}, 3 \mathrm{H}, \mathrm{CHBr}\right.$ and $\mathrm{CH}_{2} \mathrm{CH}_{2-}$ OCO), 7.03-7.15 (m, 3H, $\mathrm{ArH})$.

${ }^{13} \mathrm{C} \mathrm{NMR}\left(\mathrm{CDCl}_{3}, \delta, \mathrm{ppm}\right): 21.9,28.5,40.0,65.5,121.3$, 126.1, 128.2, 141.2, 168.8 .

\section{2, 5-Poly(3-[1-Ethyl-2-(2-bromopropionate)]thiophene) (PTBr) (3)}

Into a 300-mL three-necked round-bottom flask with $45 \mathrm{~mL}$ of $\mathrm{CH}_{3} \mathrm{NO}_{2}$ under nitrogen, 3-[1-ethyl-2-(2-bromopropionate)]thiophene $2(3.14 \mathrm{~g}, 12 \mathrm{mmol})$ was added at room temperature. With the mixture being kept under stirring, solid $\mathrm{FeCl}_{3}(7.78 \mathrm{~g}, 48 \mathrm{mmol})$ was added to the system all at once. After stirring for $1 \mathrm{~h}, \mathrm{CCl}_{4}(180 \mathrm{~mL})$ was then added to the system. The mixture was stirred for an additional $3 \mathrm{~h}$, and then precipitated in methanol, filtered, followed by subsequent Soxhlet extraction (methanol, chloroform) to recover red rubbery solid $0.95 \mathrm{~g}$ ( $30 \%$ yield) from the chloroform fraction. ${ }^{1} \mathrm{H} \mathrm{NMR}\left(\mathrm{CDCl}_{3}, \delta, \mathrm{ppm}\right): 1.96$ (br, 3H, $\left.\mathrm{CHBrCH}_{3}\right), 2.75-$ 3.32 (br, 2H, $\mathrm{ArCH}_{2} \mathrm{CH}_{2}$ ), 4.30-4.55 (br, 3H, $\mathrm{CHBr}$ and $\mathrm{CH}_{2} \mathrm{CH}_{2} \mathrm{OCO}$ ), 6.95-7.2 (br, $1 \mathrm{H}, \mathrm{ArH}, 4$ position).

${ }^{13} \mathrm{C} \mathrm{NMR}\left(\mathrm{CDCl}_{3}, \delta, \mathrm{ppm}\right): 21.9,28.5,40.0,65.5,126.5$, $128.4,129.9,132.6,134.0,135.6,137.9,169.5$.

\section{N-(3-Bromopropyl)carbazole (CPBr) (5)}

A mixture of carbazole $(25.0 \mathrm{~g}, 150 \mathrm{mmol}), 1,3$-dibromopropane $(250.0 \mathrm{~g}, 1.25 \mathrm{~mol})$, benzyltrienthylammonium chloride $(1.0 \mathrm{~g}, 4.39 \mathrm{mmol})$, benzene $(200 \mathrm{~mL})$ and $40 \mathrm{wt} \%$ aqueous $\mathrm{NaOH}(100 \mathrm{~mL})$ was stirred at room temperature for $45 \mathrm{~min}$, and then washed with water $(300 \mathrm{~mL})$. The organic layer was dried over anhydrous $\mathrm{MgSO}_{4}$ and filtered. The solvent and unreacted 1,3-dibromopropane were removed at reduced pressure. The residual product was purified by column chromatography (silica gel, toluene/hexane (1/3)). $\mathrm{CPBr}$ $(30.0 \mathrm{~g}$, yield $70 \%)$ was isolated as light yellow solid.

${ }^{1} \mathrm{H} \mathrm{NMR}\left(\mathrm{CDCl}_{3}, \delta, \mathrm{ppm}\right): 2.40$ (quintet, $2 \mathrm{H}, \mathrm{CH}_{2} \mathrm{CH}_{2} \mathrm{Br}$ ), 3.35 (t, 2H, $\mathrm{CH}_{2} \mathrm{CH}_{2} \mathrm{Br}$ ), $4.46\left(\mathrm{t}, 2 \mathrm{H}, \mathrm{NCH}_{2} \mathrm{CH}_{2}\right), 7.22-8.08$ (m, 8H, ArH).

${ }^{13} \mathrm{C} \mathrm{NMR}\left(\mathrm{CDCl}_{3}, \delta, \mathrm{ppm}\right): 31.4,33.0,59.3,111.1,118.9$, 119.0, 120.1, 122.2, 130.9.

\section{3-(N-Carbazolyl)propyl Acrylate (CPA) (6)}

CPA was synthesized according to the reported method. ${ }^{24}$ To a DMF $(200 \mathrm{~mL})$ solution of $5(15.0 \mathrm{~g}, 52.0 \mathrm{mmol})$, acrylic acid $(76.0 \mathrm{~g}, 1.05 \mathrm{~mol})$ and sodium hydrogen carbonate $(50.0 \mathrm{~g}$, $0.6 \mathrm{~mol}$ ) were added. The mixture was stirred at $60^{\circ} \mathrm{C}$ for $14 \mathrm{~h}$ and then extracted with chloroform. The organic layer was washed with water, dried over anhydrous $\mathrm{MgSO}_{4}$ and filtered. The crude product was purified by column chromatography (silica gel, chloroform). Recrystallization from methanol gave monomer $6(9.3 \mathrm{~g}$, yield $65 \%)$.

${ }^{1} \mathrm{H}$ NMR $\left(\mathrm{CDCl}_{3}, \delta, \mathrm{ppm}\right): 2.23$ (quint, $2 \mathrm{H}, \mathrm{CH}_{2} \mathrm{CH}_{2} \mathrm{CH}_{2} \mathrm{O}$ ), 4.15 (t, $2 \mathrm{H}, \mathrm{CH}_{2} \mathrm{CH}_{2} \mathrm{O}$ ), 4.41 (t, $\left.2 \mathrm{H}, \mathrm{NCH}_{2} \mathrm{CH}_{2}\right), 5.84$ (dd, $1 \mathrm{H}$, $\mathrm{CH}_{2}=$ trans to $\left.\mathrm{CO}_{2}\right), 6.14\left(\mathrm{dd}, 1 \mathrm{H}, \mathrm{CH}=\mathrm{CH}_{2}\right), 6.38(\mathrm{dd}, 1 \mathrm{H}$, $\mathrm{CH}_{2}=$ cis to $\left.\mathrm{CO}_{2}\right), 7.22-8.08(\mathrm{~m}, 8 \mathrm{H}, \mathrm{Ar})$.

${ }^{13} \mathrm{C} \mathrm{NMR}\left(\mathrm{CDCl}_{3}, \delta, \mathrm{ppm}\right): 28.2,40.0,62.3,108.5,119.1$, 120.6, 123.0, 125.8. 128.2, 130.4, 140.0, 165.9.

\section{2,5-Poly(3-[1-ethyl-2-(2-[poly(3-(N-carbazolyl)propyl Acry- late)]propionate)] thiophene) (PT-g-PCPA) (7)}

Macroinitiator $3(0.16 \mathrm{~g}, 0.6 \mathrm{mmol})$, anisole $(4 \mathrm{~mL})$ and a stir bar were placed into a $25-\mathrm{mL}$ round-bottom flask and then stirred overnight at room temperature till the polymer totally dissolved. Monomer 6 (3.25 g, $12 \mathrm{mmol}), \mathrm{CuBr}(0.18 \mathrm{~g} 1.2$ mmol) and $N, N, N^{\prime}, N^{\prime \prime}, N^{\prime \prime}$-pentamethyldiethylenetriamine $(0.21 \mathrm{~g}, 1.2 \mathrm{mmol})$ were added to flask. Flask was then placed into an oil bath at $95^{\circ} \mathrm{C}$ for $6 \mathrm{~h}$. The reaction mixture was then precipitated in methanol, filtered, followed by subsequent Soxhlet extraction (methanol, chloroform) to recover yellow powder from the chloroform fraction ( $1.0 \mathrm{~g}$, yield $29.3 \%$ ).

${ }^{1} \mathrm{H}$ NMR $\left(\mathrm{CDCl}_{3}, \delta, \mathrm{ppm}\right): 0.7-2.8$ (br, aliphatic), 3.30-4.36 (br, aliphatic), 6.68-7.50 (br, aromatic), 7.68-8.05 (br, aromatic).

${ }^{13} \mathrm{C} \mathrm{NMR}\left(\mathrm{CDCl}_{3}, \delta, \mathrm{ppm}\right): 28.0,39.7,41.9,62.5,108.5$, $119.5,123.1,125.5,128.2,140.0,174.2$.

\section{Characterizations}

Nuclear magnetic resonance $\left({ }^{1} \mathrm{H}\right.$ and $\left.{ }^{13} \mathrm{C} \mathrm{NMR}\right)$ spectra were recorded in deuterated chloroform $\left(\mathrm{CDCl}_{3}\right)$ at $50{ }^{\circ} \mathrm{C}$ on a JEOL ALPHA 500 instrument at $500 \mathrm{MHz}$, with tetramethylsilane (TMS) as the internal standard. The molecular weights of obtained polymers were determined by gel permeation chromatography (GPC) analysis with a JASCO RI-2031 detector calibrated with linear polystyrene standard. Chloroform was used as an eluent at a flow rate of $0.5 \mathrm{~mL} / \mathrm{min}$ at room temperature. Differential scanning calorimetry (DSC) analyses were performed on a Rigaku DSC-8230 under a nitrogen atmosphere at a heating rate of $10^{\circ} \mathrm{C} / \mathrm{min}$. UV-vis and PL spectra were recorded on JASCO V-570 and JASCO FP-6500 spectrophotometers, respectively. Both absorption and fluorescent measurements were carried out for a dilute solution $\left(0.02 \mathrm{mg} / \mathrm{mL}\right.$ in $\left.\mathrm{CHCl}_{3}\right)$ and a thin film. All thin films of polymers were fabricated by spin coating onto glass slides 
using a MIKASA $1 \mathrm{H}-\mathrm{D} 7 \mathrm{spin}$ coater from solution $(20 \mathrm{mg} / \mathrm{mL})$ at $1500 \mathrm{rpm}$ for $30 \mathrm{~s}$, and the thickness of the films ranged from 100 to $200 \mathrm{~nm}$. PL quantum yield of the films were measured with JASCO FP-6500 spectrophotometers equipped with an integrating sphere (JASCO ISF-531). Cyclic voltammetry (CV) were conducted on a Nikko Keisoku Model NPGFZ-2501-A potentiogalvanostat. All measurements were carried out at room temperature in a typical three-electrode cell with a working electrode (glassy carbon electrode), a reference electrode $(\mathrm{Ag} / \mathrm{AgCl})$, and a counter electrode ( $\mathrm{Pt}$ wire) at a scanning rate of $0.1 \mathrm{~V} / \mathrm{s}$. In all measurements, acetonitrile and a tetrabutylammonium tetrafloroborate $\left(\mathrm{Bu}_{4} \mathrm{NBF}_{4}\right)(0.1 \mathrm{M})$ were used as solvent and supporting electrolyte, respectively. EL devices were fabricated on indium tin oxide (ITO, 30 $\Omega$ ) covered glasses ultrasonicated sequentially in detergent, methanol, 2-propanol, and acetone. The emissive layers were deposited via spin casting from the solution in 1,2-dichloroethane $(10 \mathrm{mg} / \mathrm{mL}, 300 \mathrm{rpm}, 30 \mathrm{~s})$ and then annealed at $110^{\circ} \mathrm{C}$ for $60 \mathrm{~min}$ in vacuum. Before spin coating, the polymer solution was filtered with a $0.45-\mu \mathrm{m}$ membrane filter. The hole blocking layer bathocuproine (BPC) and metal electrodes Al were deposited onto the surface of the spin-coated polymer film by a thermal evaporation technique at $10^{-6}$ Torr through a shadow mask. The typical active area of the LEDs was $5 \mathrm{~mm}^{2}$. The current-voltage characteristics and luminance were measured with a Keithley 2400 source meter and a Topcon BM-8, respectively.

\section{RESULTS AND DISCUSSION}

\section{Copolymer Synthesis}

The synthetic route of the graft copolymer is shown in Scheme 1. ATRP initiator-substituted monomer 2 (TBr) was firstly synthesized by the reaction of 3-thiopheneethanol and 2bromopropionyl bromide in the presence of triethylamine. The macroinitiator 3 (PTBr) with ATRP initiator groups was prepared as we previously reported. ${ }^{25}$ Macroinitiator 3 was then obtained by polymerization of 2 in $\mathrm{CH}_{3} \mathrm{NO}_{2} / \mathrm{CCl}_{4}$ using $\mathrm{FeCl}_{3}$ as an oxidant. The number-average molecular weight $\left(M_{\mathrm{n}}\right)$ and glass transition temperature $\left(T_{\mathrm{g}}\right)$ of macroinitiator $\mathbf{3}$ are $20000(\mathrm{PI}=6.3)$ and $49^{\circ} \mathrm{C}$, respectively (Table I). The molecular structure of monomer $\mathbf{2}$ and macroinitiator $\mathbf{3}$ were confirmed with ${ }^{1} \mathrm{H}$ NMR spectra. From the spectrum (Figure 1a and 1b), we can clearly see the peaks at $1.96 \mathrm{ppm}$ $\left(\mathrm{CHBrCH}_{3}\right)$ and $4.30-4.55 \mathrm{ppm}\left(\mathrm{CHBr}\right.$ and $\left.\mathrm{CH}_{2} \mathrm{CH}_{2} \mathrm{OCO}\right)$ confirming the ATRP initiating groups on the backbone of macroinitiator 3. Since monomer $\mathbf{2}$ is not symmetrical, regioregular (head-to-tail) and regioirregular (head-to-head, tail-to-tail) linkages are available when thiophene rings coupled between the 2- and 5-positions, resulting in the separation of the signals at 2.75-3.32 ppm ( $\left.\mathrm{ArCH} \mathrm{CH}_{2} \mathrm{OCO}\right)$. The regionregularity is estimated to $66 \%$ in this polymer.

Carbazole containing monomer 6 (CPA) was synthesized following the reported method ${ }^{24}$ and ${ }^{1} \mathrm{H}$ NMR spectra was shown in Figure 1c. Graft copolymer 7 was prepared by grafting CPA via ATRP from the initiating sites on the

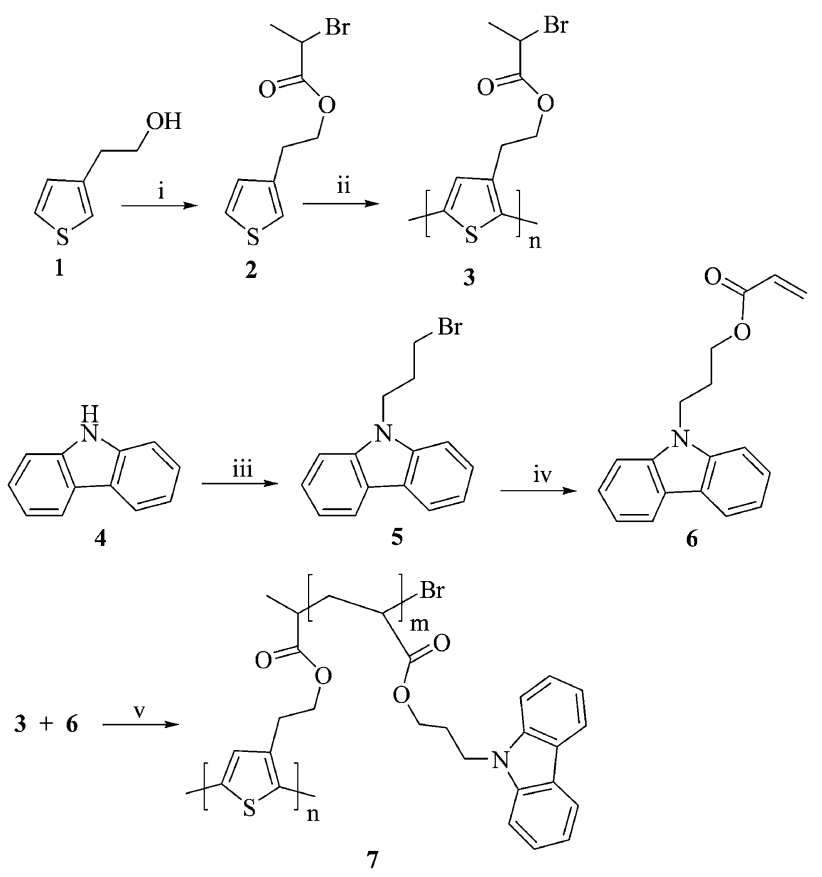

Scheme 1. The synthetic route to the graft copolymer.

Table I. Characteristics of macroinitiator and synthesized copolymer

\begin{tabular}{lccc}
\hline & $M_{\mathrm{n}}{ }^{\mathrm{a}}(\mathrm{g} / \mathrm{mol})(\mathrm{PDI})$ & $\mathrm{DP}^{\mathrm{b}}$ & $T_{\mathrm{g}}{ }^{\mathrm{c}}\left({ }^{\circ} \mathrm{C}\right)$ \\
\hline Macroinitiator 3 & $20000(6.3)$ & - & 49 \\
Graft Copolymer 7 & $33000(3.4)$ & 14 & 73 \\
\hline
\end{tabular}

a. Obtained from GPC measurements in $\mathrm{CHCl}_{3}$ using PS standards. b. DP of the PCPA side chain. Obtained by comparing the absorbencies of macroinitiator 3 and graft copolymer 7 at $413 \mathrm{~nm}$ in $\mathrm{CHCl}_{3}$. C. DSC measurements.

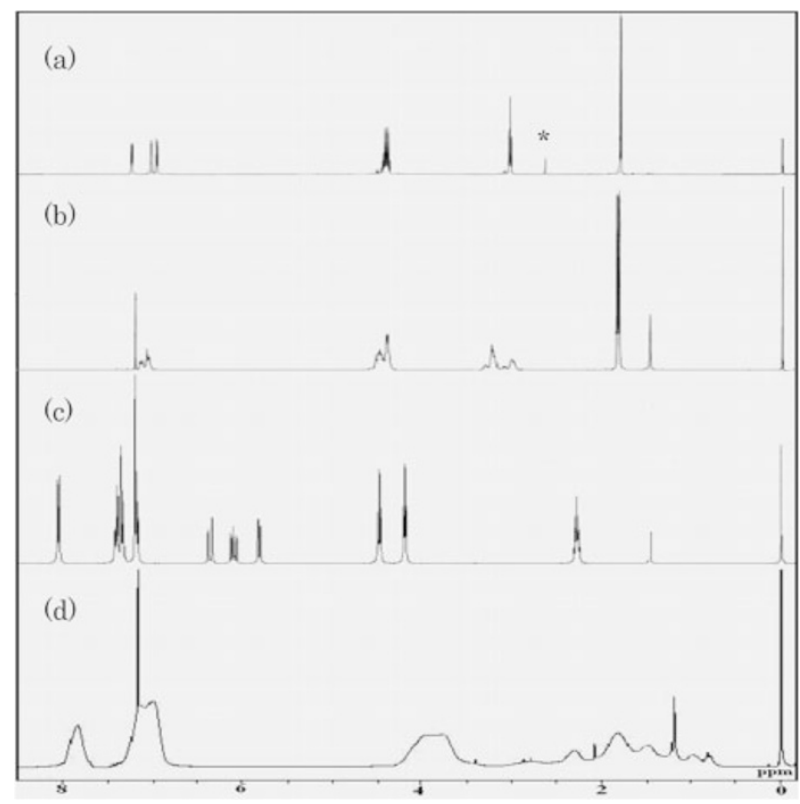

Figure 1. ${ }^{1} \mathrm{H}$ NMR spectra: (a) ATRP functional thiophene monomer 2 (TBr); (b) macroinitiator 3 (PTBr); (c) carbazole containing acrylate monomer 6 (CPA); (d) graft copolymer 7 (PT-g-PCPA). The asterisk denotes solvent impurities. 


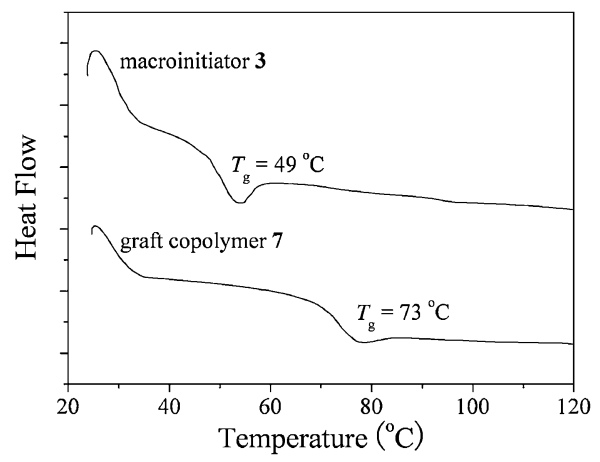

Figure 2. DSC curves of the macroinitiator $\mathbf{3}$ and graft copolymer $\mathbf{7}$ at a heating rate of $10^{\circ} \mathrm{C} / \mathrm{min}$ under a nitrogen atmosphere.

backbone of macroinitiator 3. The relative low yield $(29.3 \%)$ is due to the existence of insoluble part, resulting from the interchain coupling of side chains. Figure $1 \mathrm{~d}$ shows the ${ }^{1} \mathrm{H}-$ NMR spectra of obtained copolymer 7 . The resulting copolymer 7 shows appearance of new peaks in the region of 7.68$8.05 \mathrm{ppm}$ compared with that of macroinitiator $\mathbf{3}$, which are attributed to protons on 4,5 positions of carbazole. It was confirmed that the PCPA chains were successfully grafted onto the polythiophene backbone.

The degree of polymerization (DP) of each sidearm can be conveniently determined by comparing the UV absorbencies of macroinitiator 3 and graft copolymer 7 at $413 \mathrm{~nm}$ in solution $\left(0.02 \mathrm{mg} / \mathrm{mL}\right.$ in $\left.\mathrm{CHCl}_{3}\right)$. The absorption at $413 \mathrm{~nm}$ is coming from the PT backbone and is assumed to show the same molar absorption coefficients for both polymers. After grafting, the absorbency decreased resulted from the decrease of PT molar fraction in solution, and it is possible to calculate the increased mole of the PCPA segments, then number of PCPA repeat units per chain can be determined. The DP of graft chain determined by UV is 14 as listed in Table I.

The $M_{\mathrm{n}}$ and $T_{\mathrm{g}}$ of copolymer $\mathbf{7}$, summarized in Table I, are 33000 (PI = 3.4) and $73^{\circ} \mathrm{C}$. Comparison of the $T_{\mathrm{g}}$ values of macroinitiator $\mathbf{3}$ and copolymer 7, shown in Figure 2, clearly show the increase of glass transition temperature with incorporation of PCPA side chains, and $T_{\mathrm{g}}$ of copolymer 7 is almost equal to that of PCPA. Only one $T_{\mathrm{g}}$ observed in the DSC measurement indicates that no phase separation occurred and the glass transition of copolymer 7 is governed by PCPA sidearms. These results are reasonable since in our previous study on polythiophene- $g$-polystyrene, it was found that the $T_{\mathrm{g}}$ was almost equal to that of polystyrene when the graft density is high, although $T_{\mathrm{g}}$ was derived from the cooperative contribution of both PT backbone and polystyrene sidearms when the graft density is low. ${ }^{25}$

\section{Optical Properties}

The optical properties of copolymer 7 as well as the macroinitiator $\mathbf{3}$ were studied by UV-vis and photoluminescence spectroscopies. The UV-vis absorption and PL emission spectra of macroinitiator $\mathbf{3}$ and copolymer $\mathbf{7}$ in solution (chloroform) and film are shown in Figure 3. The maximum
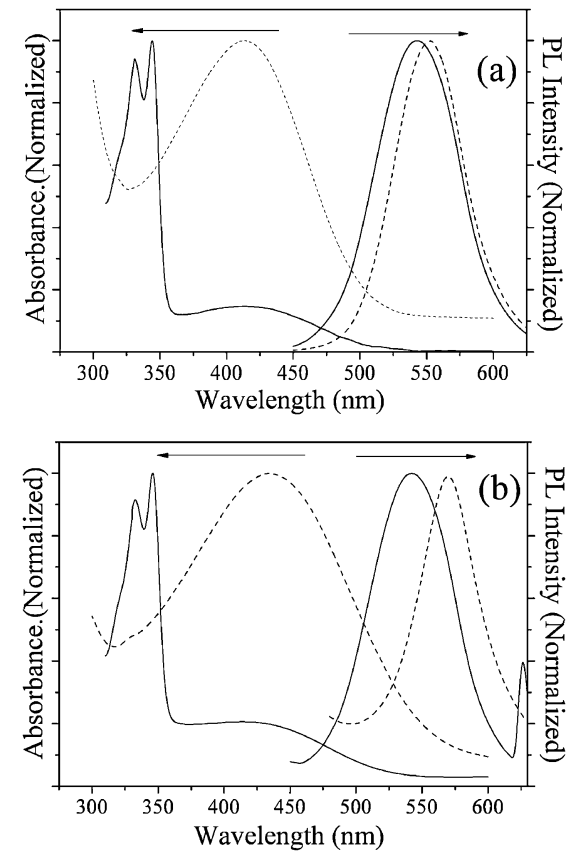

Figure 3. UV-vis and photoluminescent spectra of macroinitiator $\mathbf{3}$ (solid line) and graft copolymer 7 (dash line) (a) in $\mathrm{CHCl}_{3}$ solution and (b) in thin film form. The excitation wavelength is $413 \mathrm{~nm}$ and $460 \mathrm{~nm}$ for solution and film, respectively.

Table II. Optical data for macroinitiator and synthesized copolymer

\begin{tabular}{lccccc}
\hline & \multicolumn{4}{c}{$\lambda \max (\mathrm{nm})$} \\
\cline { 2 - 3 } & \multicolumn{2}{c}{ UV-vis absorbance } & & \multicolumn{2}{c}{ PL emission } \\
\cline { 2 - 3 } \cline { 5 - 6 } & Solution $^{\mathrm{a}}$ & Film $^{\mathrm{c}}$ & & Solution $^{\mathrm{b}}$ & Film $^{\mathrm{d}}$ \\
\hline Macroinitiator 3 & 413 & 460 & & 552 & 570 \\
Graft Copolymer 7 & $331,344,413$ & $332,346,415$ & & 543 & 542 \\
\hline
\end{tabular}

a. $0.02 \mathrm{mg} / \mathrm{mL}$ in $\mathrm{CHCl}_{3}$. b. The excitation wavelength for macroinitiator 3 and graft copolymer 7 were $413 \mathrm{~nm}$. c. Films were spin coated from solutions $(20 \mathrm{mg} / \mathrm{mL})$ at $1500 \mathrm{rpm}$ for $30 \mathrm{~s}$ with the thickness range from 100 to $200 \mathrm{~nm}$. d. The excitation wavelength for macroinitiator 3 and graft copolymer 7 were $460 \mathrm{~nm}$ and $415 \mathrm{~nm}$, respectively.

absorption and emission wavelength $\left(\lambda_{\max }\right)$ are summarized in Table II.

Figure 3a shows the optical properties of macroinitiator $\mathbf{3}$ and copolymer 7 in solution. The UV-vis spectrum of macroinitiator 3 presents the absorption maximum at $413 \mathrm{~nm}$ resulting from the $\pi-\pi^{*}$ transition of the conjugated PT backbone. While, copolymer 7 shows two strong absorption peaks at 331 and $344 \mathrm{~nm}$, corresponding to the characteristic peaks for PCPA side chains ${ }^{26}$ and a weak peak around $413 \mathrm{~nm}$ attributed to PT backbone. However, the PL emission spectra of macroinitiator 3 and copolymer 7 excited at $413 \mathrm{~nm}$ display almost identical emission profiles with a maximum at $552 \mathrm{~nm}$ and $543 \mathrm{~nm}$ respectively.

Figure $3 \mathrm{~b}$ shows the optical properties of macroinitiator $\mathbf{3}$ and copolymer 7 in a film state. The UV-vis absorption and PL emission spectra for macroinitiator $\mathbf{3}$ show an absorption maximum at $460 \mathrm{~nm}$ and emission peak at $570 \mathrm{~nm}$ (excited at $460 \mathrm{~nm}$ ), which are severely red-shifted $47 \mathrm{~nm}$ and $18 \mathrm{~nm}$ respectively compared with the values in its solution. The red 
shift in film suggested the macroinitiator exhibited an intermolecular interaction resulting from the $\pi$-stacking of thiophene rings. However, for copolymer 7, an UV-vis absorption spectrum displayed three absorption peaks at 332, 346 and $415 \mathrm{~nm}$, and PL emission spectrum depicted an emission peak at $542 \mathrm{~nm}$ (excited at $415 \mathrm{~nm}$ ). Both spectra are similar to those obtained in solution state (Figure 3a). This can be reasonably explained by the contribution of grafted sidearms, which separated the polythiophene chains and prevented interchain interaction between the backbones of the copolymer molecules. Thus a PCPA matrix was formed for effectively trapping the polythiophene in a solution conformation. The similar result was also observed in our previous study of polystyrene grafted polythiophenes. ${ }^{25}$ The photoluminescent quantum yield ( $\left.\Phi_{\mathrm{PL}}\right)$ of copolymer 7 increased to $3.8 \%$, compared with that of macroinitiator $3(0.9 \%)$.

\section{Energy Transfer Studies}

To examine the energy transfer process for copolymer 7, the selective excitation experiments were carried out. The PL emission spectra of copolymer 7, excited at $331 \mathrm{~nm}$ corresponding to the absorption maximum of PCPA side chains and $413 \mathrm{~nm}$ corresponding to the absorption maximum of polythiophene backbone, are shown in Figure 4. The emission spectra display similar profile with a maximum emission around $543 \mathrm{~nm}$, in addition to two peaks at $352 \mathrm{~nm}$ and $367 \mathrm{~nm}$ when excited at $331 \mathrm{~nm}$. Taken into account that the related emission spectra excited at $331 \mathrm{~nm}$ and $413 \mathrm{~nm}$ can be attributed to the excitation of the whole copolymer and the PT backbone, respectively, it is reasonable to attribute the peaks at $352 \mathrm{~nm}$ and $367 \mathrm{~nm}$ (in Figure 4) to the emission characteristic of PCPA side chains. Considering the aforementioned UV-vis analysis of copolymer 7 (Figure 3), it is found that the absorption peak for PT backbone at $413 \mathrm{~nm}$ overlaps with the emission from PCPA side chains observed at $352 \mathrm{~nm}$ and $367 \mathrm{~nm}$. It confirms the feasibility of the energy transfer from carbazole moieties to thiophene backbone in copolymer 7. The relative emission intensity excited at $331 \mathrm{~nm}$ is stronger than that excited at $413 \mathrm{~nm}$, both in solution and in film, which suggests that the energy transfer from the PCPA side chains to the PT backbone efficiently occurs.

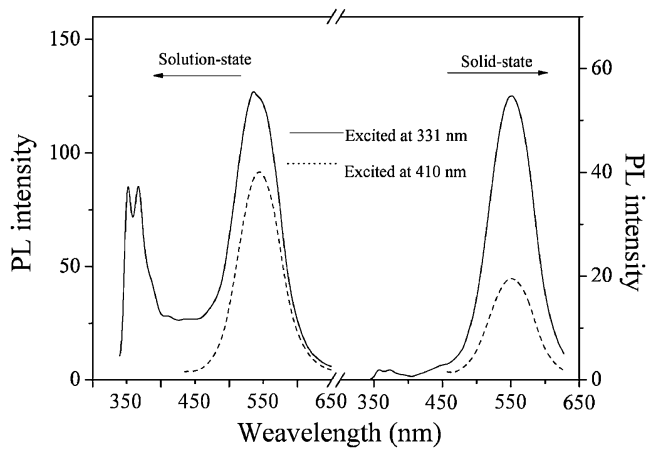

Figure 4. $\mathrm{PL}$ emission spectra of PT- $g$-PCPA in $\mathrm{CHCl}_{3}$ and in the thin films excited at the different wavelength.

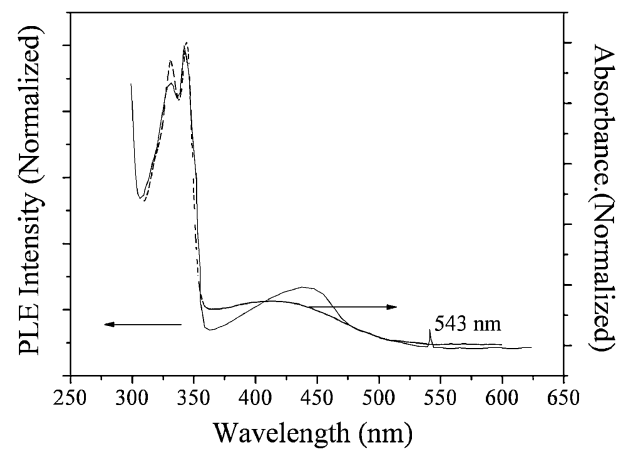

Figure 5. Photoluminescence excitation (PLE) spectrum (solid line) and UVvis spectrum (dash line) of graft copolymer 7 in $\mathrm{CHCl}_{3}$.

The energy transfer process is also evidenced by PL excitation (PLE) spectrum as shown in Figure 5. The PLE spectrum monitored at the emission maximum of copolymer 7 $(543 \mathrm{~nm})$ displays a similar profile to the absorption spectrum, indicating that both the PCPA side chains and PT backbone contribute the emission at $543 \mathrm{~nm}$.

Further investigation and comparison of PL emission spectra of copolymer 7 both in solution and in film (Figure 4) revealed that a strong residual emission from PCPA side chains still exists in solution but is almost invisible in film when excited at $331 \mathrm{~nm}$. This indicates that the energy transfer process in film is more efficient than that in solution state. The similar energy transfer systems have been also reported. ${ }^{27,28}$ According to their explanation, energy transfer in the graft copolymer obeys the Förster energy transfer mechanism and the energy transfer efficiency is mainly determined by the donor-acceptor distance $r$. Thus, in solution state where the polymer chain is extended and separated from each other, the very large $r$ leads to relatively inefficient energy transfer process. On the contrary, in the film where PT backbones and side chains are closely contacted each other, the minimized $r$ improves the energy transfer efficiency. To further describe the difference of energy transfer efficiency in both solution and film, the ratio of relative intensity of the maximal emission excited at $331 \mathrm{~nm}$ to that excited at $413 \mathrm{~nm}$ was calculated both in solution and in film. Ratios are 1.38 and 2.79 in solution and film, respectively. The lager value obtained in film further confirms the more efficient energy transfer process in the solid state.

\section{Electrochemical Properties}

The HOMO and LUMO energy levels of the conjugated polymers are closely related to their charge injection and transport properties. ${ }^{29}$ Since copolymer 7 having carbazolecontaining side chains with good hole-transporting ability, it is important to reveal the difference between macroinitiator 3 and copolymer 7 in HOMO energy levels. Here, the cyclic voltammetric $(\mathrm{CV})$ measurements performed between 0 and $+2.0 \mathrm{~V}$ are shown in Figure 6. The polymer films dip-coated on a carbon electrode are scanned in a $0.1 \mathrm{M} \mathrm{Bu}_{4} \mathrm{NBF}_{4}$ solution in acetonitrile. 


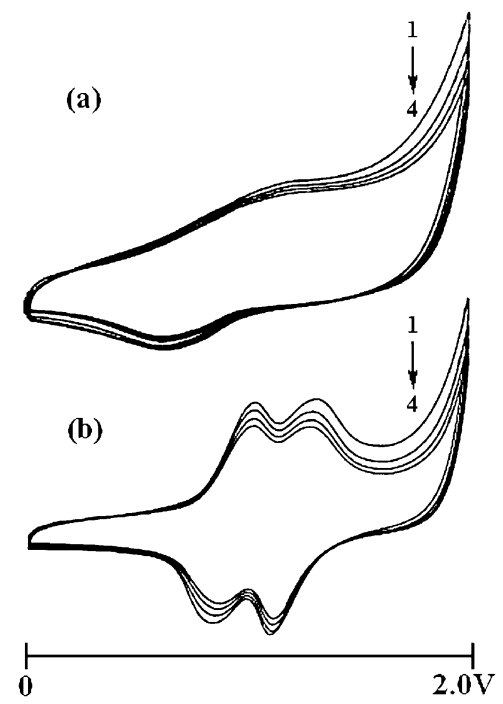

Figure 6. Cyclic voltammograms of polymers: (a) macroinitiator 3, (b) graft copolymer 7 in a $0.1 \mathrm{M}$ Bu4NBF4 acetonitrile solution at the potential range of 0 to $2 \mathrm{~V} v \mathrm{vs}$. $\mathrm{F} / \mathrm{AgCl}$. Scan times 1) the first scan, 2) the second scan, 3) the third scan, 4) the fourth scan.

Table III. Electrochemical properties of synthesized polymers

\begin{tabular}{|c|c|c|c|}
\hline & $E_{\text {onset }}^{o x}(\mathrm{~V})^{\mathrm{a}}$ & Oxidation $(\mathrm{V})^{\mathrm{a}}$ & HOMO $(\mathrm{eV})^{\mathrm{b}}$ \\
\hline Macroinitiator $\mathbf{3}$ & 0.85 & 1.26 & -5.23 \\
\hline Graft Copolymer 7 & 0.72 & $1.10,1.40$ & -5.10 \\
\hline
\end{tabular}

Macroinitiator 3 exhibited a broad oxidation wave started at $0.85 \mathrm{~V}$ and peaked at $1.26 \mathrm{~V}$, consistent with the values of polyalkylthiophenes. ${ }^{30}$ Copolymer 7 showed two reversible oxidative peaks at 1.10 and $1.40 \mathrm{~V}$, started at $0.72 \mathrm{~V}$. According to the empirical relationship proposed by Leeuw et al., the HOMO energy levels of the polymers can be obtained. ${ }^{31}$

$$
H O M O=-e\left(E_{\text {onset }}^{o x}+4.38\right)(e V)
$$

For the expedient comparison, the electrochemical data were listed in Table III. From Table III, it can be seen that the energy level of HOMO is increased by introducing the PCPA sidearms to the PT backbone, definitely indicating the benefit of the hole injection and/or transportation. ${ }^{32,33}$

\section{EL Properties}

In order to investigate the EL properties of the synthesized polymers, typical single or double-layered polymer lightemitting diodes were fabricated. Polymer film was spin-coated from a $1.0 \mathrm{wt} \%$ solution in 1, 2-dichloroethane onto an indiumtin-oxide (ITO) covered glass and the thickness was around $70 \mathrm{~nm}$. Bathocuproine as the hole blocking layer and an aluminum layer were then deposited on the top of the polymer films with the thickness of about $50 \mathrm{~nm}$ and $500 \mathrm{~nm}$ respectively.

Figure 7 shows the characteristics of the voltage-luminance (V-L) and the voltage-current density (V-I) of the devices. All the devices emitted yellowish green light coming from PT
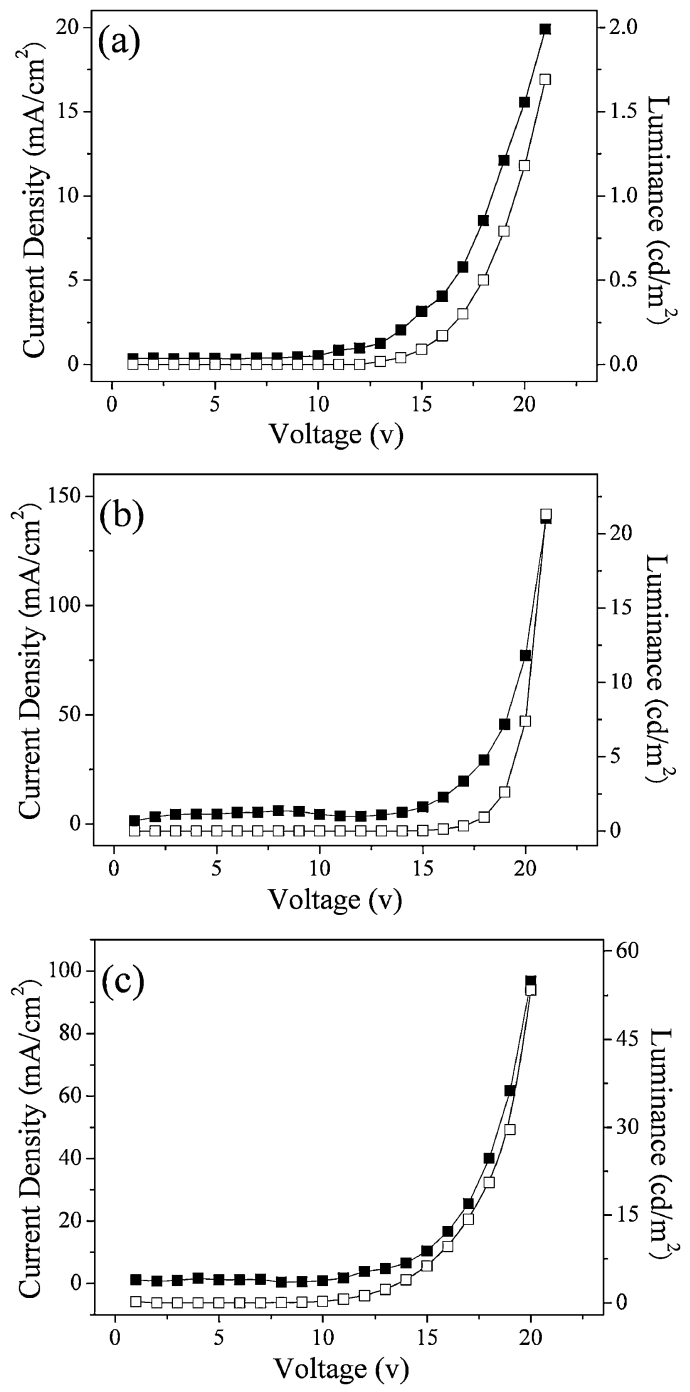

Figure 7. ( $\square$ ) Current-voltage and ( $\square$ ) luminance-voltage curves for (a) macroinitiator 3, (b) graft copolymer 7 in the device configurations of ITO/Polymer/Al and (c) graft copolymer $\mathbf{7}$ in the device configurations of ITO/Polymer/BCP/AI.

backbone. The turn-on voltage is about $14 \mathrm{~V}$, and the brightness of the devices increase with the current density. It was found that the single-layered device of copolymer 7 gives a brightness of $12 \mathrm{~cd} / \mathrm{m}^{2}$ at $20 \mathrm{~V}$ (Figure $7 \mathrm{~b}$ ), which is much higher than that of macroinitiator $3\left(2 \mathrm{~cd} / \mathrm{m}^{2}\right)$ at $20 \mathrm{~V}$ (Figure 7a). The double-layer LED device gave a low turnon voltage at $12 \mathrm{~V}$ and a maximum brightness of $53 \mathrm{~cd} / \mathrm{m}^{2}$ at $20 \mathrm{~V}$ (Figure 7c). The experience results demonstrated that the introduction of the PCPA sidearms on the PT backbone improved the EL performance.

\section{CONCLUSIONS}

A novel graft copolymer (PT- $g$-PCPA) containing polythiophene (PT) backbone and hole transporting poly[3- $(N-$ carbazolyl)propyl acrylate] (PCPA) chains is successfully synthesized by the oxidative coupling polymerization followed 
by ATRP. The molecular weight, degree of polymerization of side chain and $T_{\mathrm{g}}$ of resulting copolymer are 33000 (PDI = 3.4), 14 and $73^{\circ} \mathrm{C}$, respectively. The UV-vis and fluorescence analyses confirmed that introduction of the PCPA sidechains onto the backbone of polythiophene made it possible to trap the polythiophene backbone in a "solution-like" conformation, thus to inhibit the aggregation of polythiophene backbone effectively. The PL excitation spectrum revealed that the energy transfer process from the grafting blocks (PCPA) to the PT backbone happens in both solution and film states, and the process is more efficient in the film state. The results of the electrochemical property investigated by $\mathrm{CV}$ shows that PT$g$-PCPA has a higher HOMO level $(-5.10 \mathrm{eV})$ than macroinitiator PTBr $(-5.23 \mathrm{eV})$, suggesting that the hole injection properties of the copolymer is improved by introduction of PCPA side chains. Electroluminescence devices fabricated from the copolymer demonstrated that copolymer could act as both light emissive and hole transporting materials. It is possible that multifunction polymers afford the simple fabrication process for polymeric LED.

Received: November 11, 2007 Accepted: January 24, 2008 Published: March 12, 2008

\section{REFERENCES}

1. J. H. Burroughes, D. D. C. Bradley, A. R. Brown, R. N. Marks, K. Mackay, R. H. Friend, P. L. Burn, and A. B. Holmes, Nature, 347, 539 (1990).

2. M. Zheng, L. Ding, E. E. Gurel, P. M. Lahti, and F. E. Karasz, Macromolecules, 34, 4124 (2001).

3. Z. Yang, I. Sokolik, and F. E. Karasz, Macromolecules, 26, 1188 (1993).

4. N. C. Greenham, S. C. Moratti, D. D. C. Bradley, R. H. Friend, P. L. Burn, and A. B. Holmes, Nature, 365, 628 (1993).

5. W. U. Huynh, J. J. Dittmer, and A. P. Alivisatos, Science, 295, 2425 (2002).

6. J. Roncali, Chem. Rev., 92, 711 (1992).

7. M. R. Andersson, M. Berggren, O. Inganas, G. Gustafsson, C. J. C. Gustafsson, D. Selse, T. Hjertberg, and O. Wennerstrom, Macromolecules, 28, 7525 (1995).

8. R. D. McCullough, Adv. Mater., 10, 93 (1998).
9. M. Leclerc and K. Faid, Adv. Mater., 9, 1087 (1997).

10. D. Braun, G. Gustafsson, D. McBranch, and A. J. Heeger, J. Appl. Phys., 72, 564 (1992).

11. F. Chen, P. G. Metha, L. Takiff, and R. D. McCullough, J. Mater. Chem., 6, 1763 (1996).

12. O. Inganas, T. Granlund, M. Theander, M. Berggren, M. R. Andersson, A. Ruseckas, and V. Sundstrom, Opt. Mater., 9, 104 (1998).

13. D. Beljonne, J. Cornil, R. H. Friend, R. A. J. Janssen, and J. L. Bredas, J. Am. Chem. Soc., 118, 6453 (1996).

14. J. Shen and K. Ogino, Chem. Lett., 34, 1616 (2005).

15. R. H. Partridge, Polymer, 24, 733 (1983).

16. A. Tsuchida, A. Nagata, M. Yamamoto, H. Fukui, M. Zawamoto, and T. Higashimura, Macromolecules, 28, 1285 (1995).

17. K. Brunner, A. Dijken, H. Borner, J. J. A. M. Bastiaansen, N. M. M. Kiggen, and B. M. W. Langeveld, J. Am. Chem. Soc., 126, 6035 (2004).

18. Y. N. Li, J. F. Ding, M. Day, Y. Tao, J. P. Lu, and M. D'iorio, Chem. Mater., 16, 2165 (2004).

19. R. G. Sun, Y. Z. Wang, D. K. Wang, Q. B. Zheng, and A. J. Epstein, Synth. Met., 111-112, 403 (2000).

20. K. Kim, Y. R. Hong, S. W. Lee, J. I. Jin, Y. Park, B. H. Sohn, W. H. Kim, and J. K. Park, J. Mater. Chem., 11, 3023 (2001).

21. S. W. Hwang and Y. Chen, Macromolecules, 34, 2981 (2001).

22. A. Kimoto, J. S. Cho, M. Higuchi, and K. Yamamoto, Macromolecules, 37, 5531 (2004).

23. K. Ogino, T. Goma, D. Kageyama, H. Sato, and N. Yonezawa, J. Photopolym. Sci. Technol., 19, 419 (2006).

24. J. Hu, R. Oshima, S. Sato, and N. Seng, J. Polym. Sci., Part C: Polym. Lett., 26, 441 (1988).

25. J. Shen, K. Tsuchiya, and K. Ogino, J. Polym. Sci., Part A: Polym. Chem., 46, 1003 (2008).

26. F. Liang, T. Kurata, H. Nishide, and J. Kido, J. Polym. Sci., Part A: Polym. Chem., 43, 5765 (2005).

27. K. Y. Pu, Y. Chen, X. Y. Qi, C. Y. Qin, Q. Q. Chen, H. Y. Wang, Y. Deng, Q. L. Fan, Y. Q. Huang, S. J. Liu, W. Wei, B. Peng, and W. Huang, J. Polym. Sci., Part A: Polym. Chem., 45, 3776 (2007).

28. L. Romaner, A. Pogantsch, P. S. De Freitas, U. Scherf, M. Gaal, E. Zojer, and E. J. W. List, Adv. Funct. Mater., 13, 597 (2003).

29. E. Lim, B. J. Jung, and H. K. Shim, J. Polym. Sci., Part A: Polym. Chem., 44, 243 (2006).

30. R. D. McCullough, S. T. Nagle, S. P. Williams, R. D. Lowe, and M. Jayaraman, J. Am. Chem. Soc., 115, 4910 (1993).

31. D. M. de Leeuw, M. M. J. Simenon, A. R. Brown, and R. E. F. Einerhand, Synth. Met., 87, 53 (1997).

32. Q. Zhang, M. Yang, P. Wu, H. Ye, and X. Liu, Synth. Met., 156, 135 (2006).

33. W. C. Chen and S. A. Jenekle, Macromolecules, 28, 465 (1995). 